\title{
Information Seeking, Information Retrieval: Philosophical Points
}

\section{Gholamreza Fadaie Faculty of Psychology \& Education, University of Tehran, Iran}

\author{
ghfadaie@ut.ac.ir
}

\begin{abstract}
In this article the author argues the significance of Information retrieval (IR) against information seeking (IS). His argument is that for finding a theoretical basis information retrieval is much more effective and relevant than information seeking. In IS we either know what we want, therefore we ask for the place, quantity or quality of it. Or we do not know something exist; therefore, asking and seeking are useless. While in IR, we are aware of information and want to capture it. In fact it may be a kind of answer to the theory of "Information seeking; theory and practice" of John Budd, 2001.
\end{abstract}

Keywords: Information seeking. Information retrieval. LIS philosophical points.

\section{Introduction}

Information is a phenomenon which recently has attracted the attention of many scholars and many of them have tried to find a solution for the origin of it; that is what information is and how it appears. Hojorland and Nicolasen (2005) describing the ISO 5127: 2001 term number, 1.1.3.08 say that one way to define information is to refer to knowledge communicated. They add that the most fruitful theoretical view refers to Karpaschof's interpretation who emphasizes on the concept of release mechanisms, being systems having at their disposal a store of potential energy, and to let this energy out in specific ways. Hjorland (2000, in epistemological Lifeboat, 2005) investigates when and why the word information associated with library schools and what the theoretical implications in the shift from documents to information application.

The relationship between information and library and information studies (LIS) is more critical these days. Some hypotheses refer to communication, dialogue, discourse analysis, anomaly state of knowledge and the like. Zins(2007a) in his critical Delphi study gathered a broad investigation of many scholars' views on the nature of information as well as information science. Budd (2001, 256) seeks the theoretical foundation for information in the LIS mostly in information seeking (IS). He says:

...the necessity to devote our energy to a conceptual framework of information seeking is

Material published as part of this publication, either on-line or in print, is copyrighted by the Informing Science Institute. Permission to make digital or paper copy of part or all of these works for personal or classroom use is granted without fee provided that the copies are not made or distributed for profit or commercial advantage AND that copies 1) bear this notice in full and 2) give the full citation on the first page. It is permissible to abstract these works so long as credit is given. To copy in all other cases or to republish or to post on a server or to redistribute to lists requires specific permission and payment of a fee. Contact Publisher@InformingScience.org to request redistribution permission. rooted in the complexity of information seeking itself. A first task is to define the phenomenon; we are not served by a simplistic or mechanistic definition.

\section{Literature Review}

Searching the theoretical foundation for LIS has been the aim of scholars in recent years. Some try to find out the nature of information, others in indexing 
or recall and precision. Some try to investigate the theory in information retrieval and others in information seeking. (Zins (2007a) in his critical Delphi asked 57 scholars to define the information science reached to a variety of definitions. It is very interesting that among these different statements, we find information retrieval (IR) 11 times out of about 30 frequencies repeated while nobody in this research mentioned information seeking as a concept related to the LIS domain. Nevertheless, there has been a lot of work in information seeking and according to Budd (2001, 256-258) it is not possible to mention all of it. But as he states, too, we must not forget some famous writers in this domain. From them, he states, is Nichols Belkin, who tends the objectcentered approach with cognitive view point to information seeking, and adds that Ingeverson, although tends to cognitive view emphasizes on the necessary elements of perception and transformative nature of information that makes the knowledge structures of the seeker. David Ellis, such as Dervin is anti physicalists. They are all under the influence of the modern philosophers, such as Hubemas. Hubermas 's key point is the ability of individuals to" interpret what another person says and to respond in ways that can be interpreted by that other person". According to Budd although the experts provide a valuable help for us to understand how people recognize information need in order to seek it still there is a number of questions regarding how people can be informed and how people seek knowledge. Nevertheless he states that Bakhtin's thought is the basis for this kind of interpretation of information seeking and he evaluates that his work is of high importance. Bakhtin (1895-1975) living under the Leninist and Stalinist government in old Soviet Union and believing in religious thought stressed on the abstract ideas of self for communication. His thought is mostly consistent with phenomenology.

Argument: In this article the author argues that in the way of redefining information in order to find a solution for theoretical basis in LIS information retrieval (IR) is more relevant than information seeking (IS). Information seeking, as a theoretical basis is discussed in Budd's article: information seeking; theory and practice, so this article is going to discuss it to some extent. The author argues that information seeking, in its ultimate conception and usage is something which is dependent on information retrieval. This argument means that in any case information exists then somebody goes to seek it. But in information seeking although seeking is an informative activity it may not result to retrieval of information and may stay or remain on the of seeking activity itself. If one considers the definition of information seeking (Budd, 2001, 256) as stated "the action of individuals who consciously search for, or ask about, content that may be relevant to the individual's need", s/he will find that there must be a content (information) to be searched for or asked about.

\section{The Entity of Information}

I think before discussing on the differences of two ideas it is necessary to talk about the definition of information itself. Here by information I mean both information and knowledge and even data. Although many have discussed the subject over the ages (Vickery, 2008a, 1-3) and investigated from the root there is still ambiguity in this domain (Zins, 2007b). To my point information is produced, derived and preserved from the very beginning of our perception. That is one through encountering the world of reality finds entity or action, whatever their definitions are. A portion of systemized activity may be called process. These entities or processes do exist in the nature, (Vickery, 2008b). Immediately, or you can say at the same time one pictures it and create mental creature (Fadaie, 2008). When these mental creatures based on the creatures in the nature made by human mind or his action increase one has classify or categorize them ontologically as well as mentally and then put a name on them and then put them in one's memory, inside or outside. Suppose if we did not encounter plurality in the world and we had only a single one from every thing and suppose if what we witnessed in the world of reality we did not want to use them in our 
life in any way, then we need not to classify and name things. But as our perception is deliberately made by us and is in accordance with our willing and we know that we need things that we recognize in our lives therefore they are put in the memory in order to be retrieved, now or sometimes in future. Thus we memorize to remember (Fadaie, 2004b), as we store to retrieve. Retrieval is very important and necessary in our life and it is rooted from our very need to know for application. Knowing (Fadaie, 2008) makes us search and find the new things and new processes and put them in right places in order to be used whenever we need. Therefore an information seeking means to search something which exist, or is created by ourselves or others, now or in the past.

According to the author point view, information belongs to human being. Thus what is in the nature and nobody knows it may not be called information. They may be called laws of the nature which may be known by men through exploration or scientific investigation, here or there, now or in the future.

Also we must know that we do dual things in our perception activity; we produce information and we store it for retrieval. It means that we must differ between production of information and its retrieval. When somebody explores in the nature or in his mind and reaches to a point which is new, ontologically it is "in-form", but to bring it "in- form" epistemologically, one has to put it in a category, or classify it, name it in order to be able to retrieve it. Just like objects that we put them in distinguished places to be able to find them. You see from the beginning of our production of information / knowledge the idea of putting in a designated places appears.

Anyway for finding theoretical foundation for information whatever its definition is, the notion of retrieval is nearer to the point than the notion of seeking.

The author believes that there are many differences between these two considerations; that is; grasping to IS for theoretical basis for information science is far from regarding to IR. Some major differences are as follows:

1- Information in IS may be vague while in IR it is clear. To explain more, in information seeking one either knows what information is or he does not know it. In the latter case one seeks something which may not exist and in this case it is rationally forbidden to search what actually does not exist. In the first case, either one knows that information exists but he wants either to find the place where it is stored or he knows the information in brief and wants to find it out in detail. In both of these cases it is more suitable to refer it as information retrieval rather than information seeking. In fact in any searching for facts or investigation of the realities in the "why, when, where, how who, or whom" approaches one emphasizes that the researcher knows the information, in brief or in detail, and wants to know more by asking questions in the above mentioned question tags and the like. In other words, the question is that if the individual knows what s/he seeks, there fore the information already exists, and if he does not know what s/he seeks, then his or her query is not well structured because $\mathrm{s} /$ he searches what $\mathrm{s} /$ he does not really know. Budd (2001) in his definition of IS above mentions the "content", and this means that he is aware of the existent of the content. And, this is somehow different from what is called as anomalous state of knowledge (ASK) mentioned by him.

It is very interesting that most of rhetoricians try to link the information seeking to communication as did Dervin and Ellis (Budd, 2001, 257). It implies that before communication which is a social activity, information does not come to existence, while in information retrieval one may try to find information which $\mathrm{s} / \mathrm{he}$ is sure about its being.

Of course it is true that in many cases, information may come to being by communication but it is not restricted to one's own experience, it could be as the result of others experiences, now or in the past. One is trying to find out what may correspond to one's need. What is found it may be 
used straight forward or by manipulation by the user. The question in ASK model of Belkin et al.must be cleared out; is it for the knowledge which is really in an anomalous state and the seeker does not know what s/he is seeking or is it the state of the place where the information or knowledge is stored and one tries to find it out? Even when you make a keyword, it means that you have been familiar with the concept and it implies in its place that there has been a phenomenon as an entity or process in the real world, directly or with several means.

I think all the formulas and models investigated by Belkin et al., in their articles "ASK for information Retrieval", may be used in defining the place or places where the information is put. Place here is general and may be applied to the person (s) who knows or has the information and knowledge. Belkin and his colleagues mention (Belkin, Oddy \& Brooks, 1982, 152):

We have attempted a classification of the ASK s underlying problem statements, using easily computed characteristics of the derived associative structures. For the future, what we need is a classification with predictive power.

Note must be taken that if a seeker does not really know what $\mathrm{s} / \mathrm{he}$ wants it is not related to the ASK model, and it does not refer at the first time to IS or IR. These efforts from the seeker side is to clear what $\mathrm{s} /$ he wants and the struggle of reference librarian or information manager who tries to purify the seeker 's question and canalize his or her want is something before the process of information retrieval or even information seeking and it may not be called anonymous state of knowledge. It is just for preparation. It is like somebody who wants to build a building. It is obvious that before beginning to the right task one has to designate and clean up the place and define or limit the borders.

As it was mentioned in information seeking by Budd $(2001,258)$ one is engaged with other and according to Habermas "the key to understanding, is the ability of individuals to engage in genuine dialogue." And Bakhtin (Budd, 259) explains that communication is dependent to dialogue. Dialogue purifies the state of the need and does not relate directly to the information and knowledge existed. By dialogue with the experts such as librarian, the seeker tries to specify and clear out the need, find out the amount of knowledge /information that s/he needs or the quality of place the knowledge is stored. More than that

2- Information in IS refers to the users who need information, while in IR it comprises the users and the owner of information. What enforces this idea is the Budd's explanation of Belkin's theory which states (256-257):

He writes that it is reasonable to expect an information seeker to describe goals, problems, and knowledge, and that such a description can be represented and used in comparison with document representations for retrieval purposes.

3-Information in IS refers to outside of the store of information while in IR it refers to inside and outside and it is independent from seeker's want and willing. It means that the information does not change according to the seeker's will but it is the seeker who must adapt his/her need to the information existed. For example s/he, for retrieval or after retrieval with the help of librarian or information specialist may add, substract, mix or multiply the information and produce a new one for himself and/ or others.

4- In IS one may reach the result while in the IR, one usually must get the result, because it is supposed that the information exist and one seeks its place of storage. The failure refers to the way one asks, the methods the librarian / information manager chooses to find the information and the way that the classifier/ indexer have chosen to store it. The separation of indexer/classifier with the needs of users and neglecting the situation and environment where the information seekers live in is decisive and critical. 
5- In IS search being on the way to find something is important by itself because being on the way of reaching something though one is not sure about the result is part of the task of information seeking even if one does not reach his/her need, while in the IR reaching the result is important and vital. In fact in IR the classification/indexing are for the sake of retrieval not for its own sake. If sometimes in the situation of danger one may try to store something not to be stolen or destroyed in order to be used by the coming generation, but in the ordinary situation the information and knowledge are stored in order to be retrieved. If the retrieval in the best way possible is not the case there fore the information stored are out of use and maybe put in the waste basket.

6- In IS, as it is defined by dialogue and communication it may be fully subjective and in the realm of imagination or epistemology while in IR it is in the fields of both ontology and epistemology. Because in IR we accept that there has been something as information and we want to retrieve it while in the IS we may not know if there is something as information. We are just seeking information in order to find it in so called ASK condition. In this case it is more likely the state of production of information not its retrieval. In this case we do not seek information while we create it, but after the production we store it in order to be retrieved. And these are two, and may have separate rules, methods and methodologies.

7- In IS one does not tend to classification at first stage and it must be discovered or one should create it while in IR, classification is created before because one(s) who is responsible for retrieval put created information in somewhere and knew that users need it and there fore consciously put it in a right place by hand or by a system, simple or complicated. That is from the first time when one stores the information $\mathrm{s} /$ he has selected an appropriate classification scheme to be able to retrieve it, individually or socially.

8- In IS, the seeker may not have an image of inform (ion) itself, because it is supposed that $\mathrm{s} / \mathrm{he}$ does not know any thing and has not any idea about it, while in IR one is supposed to know the inform (ion) as "in-form" has been created before and universal is the result of such activity. To explain more every thing in the realm of ontology is in-form but when it comes in the realm of epistemology we must have some similar ones and then one should derive the universal from them. Without which the universal could not come into being (Fadaie, 2008). Universals are the result of grouping similar things or processes. Even "this, that, these and those" tags are the first range of our knowing for pointing to things that are similar in being near us or far from us and they are the first universals which are made in the realm of epistemology in order that one can refer to what has known before ontologically.

9- In IS if one does not reach the result s/he may be disappointed and may cease searching while in IR the result must be obtained and if somebody does not find the information the search methodology may be changed to get the result. In this case one tries more and may experience other ways and consult with experts to get better idea for the place(s) where the information is stored.

10- In IS usually one needs the second person for dialogue, while in IR the second person may be the researcher himself. In other words, according to some scholars (Budd, 257-259), there is a link between information seeking and communication. Brenda Dervin as well as Ellis arguing against physicalists supports this idea. According to them physicalists have two assumptions: "one is that information can be treated like a brick; the other is that people can be treated like empty baskets into which bricks can be thrown. Habermas believes that it is the dialogue which engages the people to understand concepts. Michael Holquist criticing Bakhtin's dialogic communication emphasizes monologic communication. Bakhtin also reminds that "the exact experiences constitute a monologic form of knowledge: the intellect contemplates a thing and compounds upon it."

11- In IS one may discover the information by dialogue or communication or create it by interpretation, while in IR it is supposed that the information exists or is already created, then one tries to 
discover the place where it is put or classified. If the communication and discourse works it is for finding the place(s) of information.

If one argues that the information is something as production because according to some scholars such as Habermas it is the seeker who interprets the information, the answer is that if the information searched by the seeker is dependent on his/her interpretation the information is created and it is a new one and it is not in the realm of IR, obviously then for the next time one tries to re-find it. When you produce something at the moment, immediately you add it to the store in order to be retrieved in a time and some where. The new interpretation is something new, and it may differ with the need which an individual looks for. Some may confuse the task of IS with IR. Budd describing Kuhlthau states (257):

She distinguishes between an objectivist approach to information seeking and a more phenomenological one. As she says," the traditional approach is limited to the task of locating sources and information but does not take into account the tasks of interpreting, formulating and learning in the process of information seeking. She suggests a model that combines what the content contains with what the information seeker does with content. The model is, consciously or no, derived from Jurgen Habermas's claim that understanding arises from the conjoined interpretation of language and experience. Some of Habermas's elements of life world are evident in Kuhlthau's model. She writes" within information search process, the user interprets information to construct new understandings and knowledge that add valuable information for addressing problems and making judgments.

Here, as told before the question is this if the information exists, therefore information retrieval is important and principal, and if it does not exist how one could search for it. But what shows the passage is that by seeking information one may interpret it and find out new information or understanding. It is in the realm of creation and production of information, and not in retrieval domain.

12- IS may be one sided and subject oriented, that is dependent mainly on the dialogue with potential user not information provider or owner, because s/he needs something, not the information provider is aware of it, while IR is object and subject oriented. In the latter case both sides try to retrieve the information which they are sure that it exists. The conception of life world as is in phenomenology support this idea that in retrieval what is important is the life and whatever is related to it. While in seeking information one may try to search whatever that may not exist. The life (Budd, 2001, 258), is a world of practice and praxis. Practice refers to action, making and doing while praxis tends to social action, production of goods, exchange of goods, and distribution of goods and one may consider them as subjective. In the opposite side, many scholars try to reject the physicalist ideas which, I think it must be considered in its place. The post modernists try to focus on cognition. It is to be considered that rejection of positivist ideas is because of their exclusive views, and the post modernists including phenomenologist take another side which is not complete. The right stand, the author believes, is to adhere both sides; that is outsides and insides.

so phenomenology is very important here and Bakhin's communication theory emphasizes on it. Full realization between people as between I and other, because of thinking, feeling, motioning, understanding, and ... stands on communication. Communication necessitates the discourses and the importance of language. Budd states that Mohanty, expressing the relationship of human existence and the world around talks of world of practice (of action, making and doing) and praxis (of social action, of production of goods, exchange of goods, and distribution of goods) as the two bases of world of reality. He adds that this is what stated by most proponent philosophers such as Edmund Husserl, Martin Heidegger which reformulated by Habermus as the idea of life world. 
Budd $(2001,258)$ mentioning the idea of Bakhtin's phenomenology and his theory of being expresses some key elements which are important in librarianship. These are as:

Being (which includes consciousness along with our relation to the world); perception (in the sense that we are part of the world we perceive, so the subject-object dichotomy is a false one); intentionality (Human action is consciously directed toward something, with a desired end in mind); and recognition of the interrelation between self and other (not only am I a subject, but the other is also a perceiving subject).

All these items may be used in IR system while they are used in IS just for finding out the intentionality of second person to purify his/her want. And if so they are all for preparation and is not in the context of IR system.

13-IS refers to phenomenology while IR is fully related to domain analysis. This manes that according to phenomenologists one through discourse, communication and dialogue try to find something as information and then $\mathrm{s} /$ he may try to consult with librarian or information specialists to reach his/her needs; while in IR it is supposed that the librarian or information specialists is fully aware of his/her storage and is fully able to use the search tools to find the users' needs for information or knowledge. In some cases in IS one tries to clear out the domain of the information needs by dialogue, discourse and the like then IR process may begin. For example if a user wants some information about classification, if at first he does not know the term or the concept by IS techniques through retrieval activities, s/he may reach to the point that his/her need is classification. Then $\mathrm{s}$ /he may try to define that this classification which belongs to several domain is library classification (Fadaie, 2004b).

14- In IS the librarianship may be defined as a task of searching and retrieval may not occur while in IR the retrieval is the ultimate aim and search is a tool for it. To explain more, in IS as a foundation theory for LIS one tries to reach a point of view by discourse, communication and dialoge while in IR one knows that the LIS discipline is to retrieve the information stored and its aim is to find it out through sophisticated classification scheme or indexing or other searching tools.

15- In IS the information may be defined as the knowledge how, while, in IR it is knowledge how and the knowledge who and the knowledge why,... This means that by information retrieval one tries to find the authors, as well as places, time, qualification of information while in IS one may usually focus on the "how" situation of information, because in dialogue one tries to find out the others interpretation and this interpretation mostly emphasizes on the "how" situation.

\section{Conclusion}

As stated above the aim of this article was to define that for searching a theoretical foundation for LIS, IR is more relevant than IS. In IR it is assumed that information exists and the librarian or information specialist is responsible to retrieve it or introduce an organized system that every user is able to search and find his /her need easily. Communication, discourse, and dialogism which is inherent in IS are for preparation in IR system and they are not the main task in LIS. This approach can make a theoretical basis for LIS by IR rather than IS which originally may not reach to information. Because in IS either information exist then the seeker ask for the place of storage, or information does not exist or the seeker is not aware of that therefore asking of what is not existed or is in anomaly state can not be asked for. IS may lead to production of information rather than retrieval and scholars statement about communication, discourse and dialogism support it.

\section{References}

Belkin, N. J., Oddy, R. N., \& Brooks, H. M. (1982a). ASK for information retrieval: Part 1.Back ground and theory. Journal of Documentation, 38(2). 
Information Seeking, Information Retrieval

Belkin, N. J., Oddy, R. N., \& Brooks, H. M. (1982b). ASK for information retrieval: Part 11.Results of a design study. Journal of Documentation, 38(3).

Budd, J. M. (2001). Information seeking in theory and practice: Rethinking public services in libraries. Reference \& User Services Quarterly, 40(3).

Budd, J. M. (2005). Epistemological lifeboat. In http://www.db.dk/jni/lifeboat/Concepts/Information.htm

Fadaie Araghi, G. (2004a). A dynamic look towards classification and retrieval. Cataloging and Classification Quarterly, 38(1).

Fadaie Araghi, G. (2004b). A new scheme for library classification. Cataloging and Classification Quarterly, 38(2).

Fadaie, G. (2008). The influence of classification on wolrdview and epistemology. Proceedings of the Informing Science \& IT Education Conference (InSITE) 2008...

Hojorland \& Nicolasen. (2005). Epistemological lifeboat. In http://www.db.dk/jni/lifeboat/Concepts/Information.htm

Vickery, B (2008a). What general information theory do we need? In: E: Ivikerylinfotheory.htm

Vickery, B (2008b). Information science. Pt.1. In E: |vikerylinfoscil. htm

Zins, H. (2007a).Classification scheme of IS; Twenty eight scholars map the field. JASIST, 58(5).

Zins, H. (2007b). Conceptual approaches for defining data, information, and knowledge. JASIAT, 58(4).

\section{Biography}

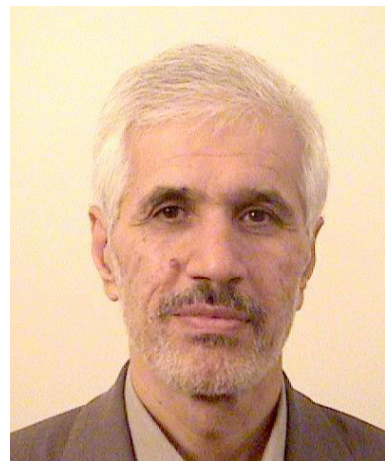

Gholamreza Fadaie, Ph.D in LIS is a LIS full professor and the Dean of newly established LIS Faculty, University of Tehran, Iran. He is 65 years old and has about 19 books and more than 30 articles in Persian. Also he has several articles in English and Arabic. Four of his English articles have been published in Cataloging and Classification Quarterly journal in 2004 and 2005. He has some new idea about classification and philosophy of LIS. 